\title{
Current clinical guideline definitions of airflow obstruction and COPD overdiagnosis in primary care
}

\author{
T.R.J. Schermer*, I.J.M. Smeele”, B.P.A. Thoonen ${ }^{*}$, A.E.M. Lucas ${ }^{+}$, J.G. Grootens*, \\ T.J. van Boxem ${ }^{\S}$, Y.F. Heijdra ${ }^{f}$ and C. van Weel*
}

ABSTRACT: The aim of the present study was to establish the agreement between two recommended definitions of airflow obstruction in symptomatic adults referred for spirometry by their general practitioner, and investigate how rates of airflow obstruction change when prebronchodilator instead of post-bronchodilator spirometry is performed.

The diagnostic spirometric results of 14,056 adults with respiratory obstruction were analysed. Differences in interpretation between a fixed 0.70 forced expiratory volume in one second (FEV 1 )/ forced vital capacity (FVC) cut-off point and a sex- and age-specific lower limit of normal cut-off point for this ratio were investigated.

Of the subjects, $53 \%$ were female and $69 \%$ were current or ex-smokers. The mean postbronchodilator $\mathrm{FEV}_{1} / \mathrm{FVC}$ was 0.73 in males and 0.78 in females. The sensitivity of the fixed relative to the lower limit of normal cut-off point definition was $97.9 \%$, with a specificity of $91.2 \%$, positive predictive value of $72.0 \%$ and negative predictive value of $99.5 \%$. For the subgroup of current or ex-smokers aged $\geqslant 50 \mathrm{yrs}$, these values were $100,82.0,69.2$ and $100 \%$, respectively. The proportion of false positive diagnoses using the fixed cut-off point increased with age. The positive predictive value of pre-bronchodilator airflow obstruction was $74.7 \%$ among current or ex-smokers aged $\geqslant 50 \mathrm{yrs}$.

The current clinical guideline-recommended fixed 0.70 forced expiratory volume in one second/ forced vital capacity cut-off point leads to substantial overdiagnosis of obstruction in middle-aged and elderly patients in primary care. Using pre-bronchodilator spirometry leads to a high rate of false positive interpretations of obstruction in primary care.

KEYWORDS: Chronic obstructive pulmonary disease, diagnostics, lung function measurements, primary care

hronic obstructive pulmonary disease (COPD) is a respiratory condition that is predominantly caused by smoking, and is characterised by airflow obstruction that is progressive in nature and not fully reversible [1]. Recent estimates for the population prevalence of COPD in adults aged $>40$ yrs range $11-26 \%$ for countries throughout the world [2]. As the majority of patients with COPD are diagnosed and managed in primary care, timely diagnosis and subsequent staging both require primary care spirometry in order to confirm the presence and severity of airflow obstruction [3].

Airflow obstruction in COPD is present when a patient shows a disproportionate reduction in the maximal airflow from the lungs in relation to the maximal volume that can be displaced from the lungs [4]. According to current COPD guideline recommendations for primary $[5,6]$ and secondary care $[1,7,8]$, this is determined by measuring the forced expiratory volume in one second (FEV1)/forced vital capacity (FVC) ratio. Without exception, the guidelines recommend a fixed 0.70 cut-off point for FEV1/FVC in deciding whether or not airflow obstruction is present, regardless of the sex and age of the subject involved. However, it is well documented that ageing is associated with a range of postural and physiological changes that influence respiratory function in both sexes [9] Several reports from studies in healthy nonsmokers indicate that the cut-off point for an abnormal FEV1/FVC ratio indeed depends upon the sex and age of an individual [10-12]. Hence the use of the fixed $0.70 \mathrm{FEV} 1 / \mathrm{FVC}$ cut-off point may lead to a substantial proportion of middle-aged and elderly
AFFILIATIONS

Depts of * General Practice, and

${ }^{f}$ Lung Diseases, Radboud University Nijmegen Medical Centre, Nijmegen,

${ }^{\#}$ General Practice Laboratory

Foundation Etten-Leur/Breda,

Etten-Leur

"General Practice Laboratory East, Velp,

+Eindhoven Diagnostic Centre,

Eindhoven, Eindhoven, and

${ }^{\S}$ Dept of Lung Diseases, Franciscus

Hospital, Roosendaal, The

Netherlands.

CORRESPONDENCE

T.R.J. Schermer

Dept of General Practice - 117/HAG Radboud University Nijmegen

Medical Centre

P.0. Box 9101

6500 HB Nijmegen

The Netherlands

Fax: 31243541862

E-mail: T.Schermer@hag.umcn.nl

Received:

December 182007

Accepted after revision:

May 282008

STATEMENT OF INTEREST

Statements of interest for

T.R.J. Schermer and C. van Weel, and the study itself can be found at www.eri.ersjournals.com/misc/ statements.shtml 
males and females unjustly being considered to have COPD. Indeed, this has been shown in several general population studies [13-18].

Taking the point of view that a cut-off value for any physiological or biochemical index used in medicine should be able to reliably differentiate between normal and abnormal function, it seems that the "one size fits all" approach with a fixed FEV1/FVC cut-off point for everyone is inadequate. A definition based on the lower limit of normal (LLN) of the FEV1/FVC, as observed in an appropriate reference population, is regarded the scientifically justified and preferred way of rendering justice to the sex and age dependency of the ratio [4].

Since COPD is generally first diagnosed in primary care, the issue of which definition to use in deciding whether or not airflow obstruction is present is especially relevant for general practitioners (GPs). Given the frequent comorbidity that occurs in older current or ex-smokers, such as, for example, heart failure [19], using an inappropriate cut-off point further increases the chance of an incorrect diagnosis and subsequent, potentially avoidable, healthcare costs.

The aim of the present study was to compare the agreement between the two recommended definitions of airflow obstruction (i.e. the clinical guideline-recommended fixed cut-off point for FEV1/FVC versus the LLN cut-off point) and severity classification based on predicted FEV1 in a population of subjects with respiratory complaints but without a prior diagnosis of chronic respiratory disease who were referred by their GP to a primary care diagnostic centre for spirometry. It was also investigated how rates of airflow obstruction in this study population change when pre-bronchodilator instead of post-bronchodilator spirometric values are used.

\section{METHODS}

\section{Study population}

The present study was based on all of the available spirometric results (October 2001 to May 2007) from the General Practice Laboratory Foundation Etten-Leur/Breda (Etten-Leur, the Netherlands; SHL), a regional primary care diagnostic centre that has provided a range of diagnostic and healthcare services (including spirometry) for $>330$ GPs in the south-western area of the Netherlands since 1997. GPs refer patients they suspect of having COPD or asthma to the SHL for diagnostic spirometry on the basis of presentation with respiratory symptoms or other problems for which the GP considers spirometry to be indicated. The SHL performs $\sim 5,000$ spirometric tests annually. Approximately half are of the tests are for diagnostic purposes, the other half are being carried out as part of the regular monitoring of patients with COPD or asthma. The spirometric results and accompanying demographic (sex and age), anthropometric (height and weight) and medical history information (smoking habit and respiratory symptoms (sputum, cough, dyspnoea and exacerbations during the past year)) are recorded during each visit using a standard format. For the current study, all subjects for whom a post-bronchodilator spirometric test result was available were selected. If two or more spirometric results were available for a particular subject, only the first one was used for the present study. From this, the subset of subjects aged $\geqslant 50$ yrs that were current or ex-smokers were selected because of their higher prior probability of being diagnosed with COPD. The medical ethics review board of the Radboud University Medical Centre Nijmegen (Nijmegen, the Netherlands) approved the present study. Since only routine lung function data were used for the present retrospective database analysis and the investigators had no access to the patients' medical records or information on patient identity, no written informed consent was obtained.

\section{Measurement and definition of airflow obstruction}

The SHL operates in 21 different locations where spirometric testing is performed. Five certified lung function technicians perform these tests. Each of them performs a minimum of 100 spirometric tests annually. The technicians are regularly supervised in central meetings. Personal computer-based digital volume sensor spirometers (SpiroPerfect $₫$; WelchAllyn, Delft, the Netherlands) are used at all locations. This spirometer satisfies American Thoracic Society (ATS) standards [20]. The lung function technicians always use the same spirometer, and all follow a standard operating procedure for calibration of the spirometer on a daily basis using a 1-L syringe. Within-test volume deviations of $<3 \%$ are considered acceptable. Air temperature and ambient pressure are measured and entered into the spirometric software in order to correct for body temperature and ambient pressure saturation [20]. Patient instruction, assessment of acceptability of forced expiratory manoeuvres and criteria for test reproducibility are based on ATS recommendations [20]. Pre- and post-bronchodilator measurements are performed with subjects seated at rest before and $15 \mathrm{~min}$ after administration of four doses of $100 \mu \mathrm{g}$ aerosolised salbutamol by Volumatic ${ }_{\circledR}$ spacer (GlaxoSmithKline, Brentford, UK). The prediction equations of the European Community for Steel and Coal (ECSC) [12], which are applied quite universally in Europe, were used to determine predicted values of FEV1 and FEV1/FVC. In order to calculate sex-, age- and height-specific predicted values of FEV1, a correction factor of 1.08 was applied [21], as recommended for the Dutch population in the current COPD guideline of the Netherlands College of General Practitioners [6].

\section{Analysis}

The post-bronchodilator FEV1/FVC was used to determine whether or not airflow obstruction was present in the study subjects. The following two definitions of obstruction were used.

1) Fixed cut-off point definition: FEV1/FVC of $<0.70$. This is the definition that is currently recommended in all major clinical COPD guidelines $[1,7,8]$.

2) LLN cut-off point definition: FEV1/FVC below the sex- and age-specific LLN. This is the definition recommended by lung function experts [4]. The LLN was determined by subtracting the predicted FEV1/FVC from the measured FEV1/FVC in each study subject and dividing this difference by the residual SD (0.0717 in males and 0.0651 in females) derived from the ECSC reference population [12]. When the resulting SD score was $<-1.645$, airflow obstruction was present according to the LLN definition. This corresponds to the estimated 5th percentile.

A similar procedure was followed in determining severity of airflow obstruction based on either the FEV1 expressed as a 


\begin{tabular}{|c|c|c|c|c|}
\hline \multirow[t]{3}{*}{ TABLE 1} & $\begin{array}{l}\text { istics of stu } \\
\text { of older } \mathrm{Cl}\end{array}$ & $\begin{array}{l}\text { udy sampl } \\
\text { urrent or e }\end{array}$ & $\begin{array}{l}\text { e and the } \\
\text { x-smokers }\end{array}$ & \\
\hline & \multicolumn{2}{|c|}{ Total population } & \multicolumn{2}{|c|}{ Subgroup } \\
\hline & Males & Females & Males & Females \\
\hline Subjects n & 6597 & 7459 & 3473 & 2543 \\
\hline Age yrs & $54.2 \pm 15.2$ & $51.9 \pm 15.1$ & $64.5 \pm 8.9$ & $61.9 \pm 8.3$ \\
\hline \multicolumn{5}{|l|}{ Age range $\%$} \\
\hline $21-30 \mathrm{yrs}$ & 7.3 & 9.3 & & \\
\hline $31-40$ yrs & 13.9 & 15.5 & & \\
\hline $41-50$ yrs & 18.1 & 21.4 & 1.6 & 2.7 \\
\hline $51-60$ yrs & 23.5 & 23.4 & 36.4 & 47.5 \\
\hline $61-70$ yrs & 21.0 & 18.2 & 34.3 & 32.0 \\
\hline $71-80$ yrs & 13.6 & 10.1 & 23.4 & 15.5 \\
\hline$\geqslant 81$ yrs & 2.6 & 2.1 & 4.4 & 2.2 \\
\hline Height $\mathrm{m}$ & $1.77 \pm 0.08$ & $1.65 \pm 0.07$ & $1.75 \pm 0.01$ & $1.63 \pm 0.06$ \\
\hline \multicolumn{5}{|l|}{ Smoking status \% } \\
\hline Never-smoker & 20.3 & 35.7 & & \\
\hline Ex-smoker & 42.8 & 28.3 & 62.3 & 53.0 \\
\hline Current smoker & 32.9 & 32.1 & 37.7 & 47.0 \\
\hline Missing & 4.0 & 4.0 & & \\
\hline \multicolumn{5}{|l|}{ Respiratory symptoms \%" } \\
\hline Exercise-related dysp ${ }^{+}$ & 60.4 & 69.1 & 64.0 & 68.8 \\
\hline Nocturnal dysp & 21.3 & 24.6 & 19.4 & 22.0 \\
\hline Cough & 66.3 & 73.6 & 67.2 & 73.1 \\
\hline Sputum & 61.5 & 59.2 & 62.9 & 60.9 \\
\hline $\begin{array}{l}\text { Exacerbation(s) in } \\
\text { past year }\end{array}$ & 37.6 & 47.1 & 35.8 & 47.7 \\
\hline \multicolumn{5}{|l|}{ FEV $_{1}$} \\
\hline Pre-bronch L & $2.83 \pm 0.98$ & $2.18 \pm 0.70$ & $2.35 \pm 0.81$ & $1.77 \pm 0.57$ \\
\hline Post-bronch L & $3.00 \pm 0.98$ & $2.31 \pm 0.70$ & $2.50 \pm 0.81$ & $1.87 \pm 0.56$ \\
\hline Post-bronch \% pred & $77.3 \pm 18.3$ & $81.5 \pm 17.5$ & $72.4 \pm 19.6$ & $75.7 \pm 19.5$ \\
\hline \multicolumn{5}{|l|}{ FVC } \\
\hline Pre-bronch L & $3.97 \pm 1.06$ & $2.87 \pm 0.77$ & $3.49 \pm 0.91$ & $2.47 \pm 0.62$ \\
\hline Post-bronch L & $4.09 \pm 1.03$ & $2.94 \pm 0.75$ & $3.62 \pm 0.88$ & $2.55 \pm 0.60$ \\
\hline Post-bronch \% pred & $83.0 \pm 14.2$ & $83.6 \pm 13.9$ & $80.7 \pm 15.3$ & $81.6 \pm 15.1$ \\
\hline \multicolumn{5}{|l|}{$\mathrm{FEV}_{1} / \mathrm{FVC}$} \\
\hline Pre-bronch & $0.70 \pm 0.13$ & $0.75 \pm 0.11$ & $0.67 \pm 0.13$ & $0.71 \pm 0.12$ \\
\hline Post-bronch & $0.73 \pm 0.13$ & $0.78 \pm 0.11$ & $0.68 \pm 0.13$ & $0.73 \pm 0.12$ \\
\hline
\end{tabular}

Data are presented as mean $\pm \mathrm{SD}$, unless otherwise indicated. dysp: dyspnoea; FEV1: forced expiratory volume in one second; bronch: bronchodilator; FVC: forced vital capacity; \% pred: \% predicted. ${ }^{\#:}$ 6,016 current or ex-smokers aged $\geqslant 50 \mathrm{yrs}^{\prime}{ }^{\top}$ : based on a $15 \%(n=2,100)$ random sample of study subjects; ${ }^{+}: \geqslant 2$ on UK Medical Research Council scale.

percentage of the predicted value $[1,7,8]$ or the LLN based on the distribution of FEV1 [4] in the reference population [12]. Finally, $3 \times 3$ tables were constructed in order to compare the presence and severity of airflow obstruction based on the fixed FEV1/FVC cut-off point and percentage predicted FEV1 classification (i.e. no, mild and moderate-to-very severe obstruction) on the one hand and LLN of FEV1/FVC and FEV1 on the other.

The sensitivity, specificity, positive and negative predictive value [22], and the $95 \%$ confidence intervals (CIs) were
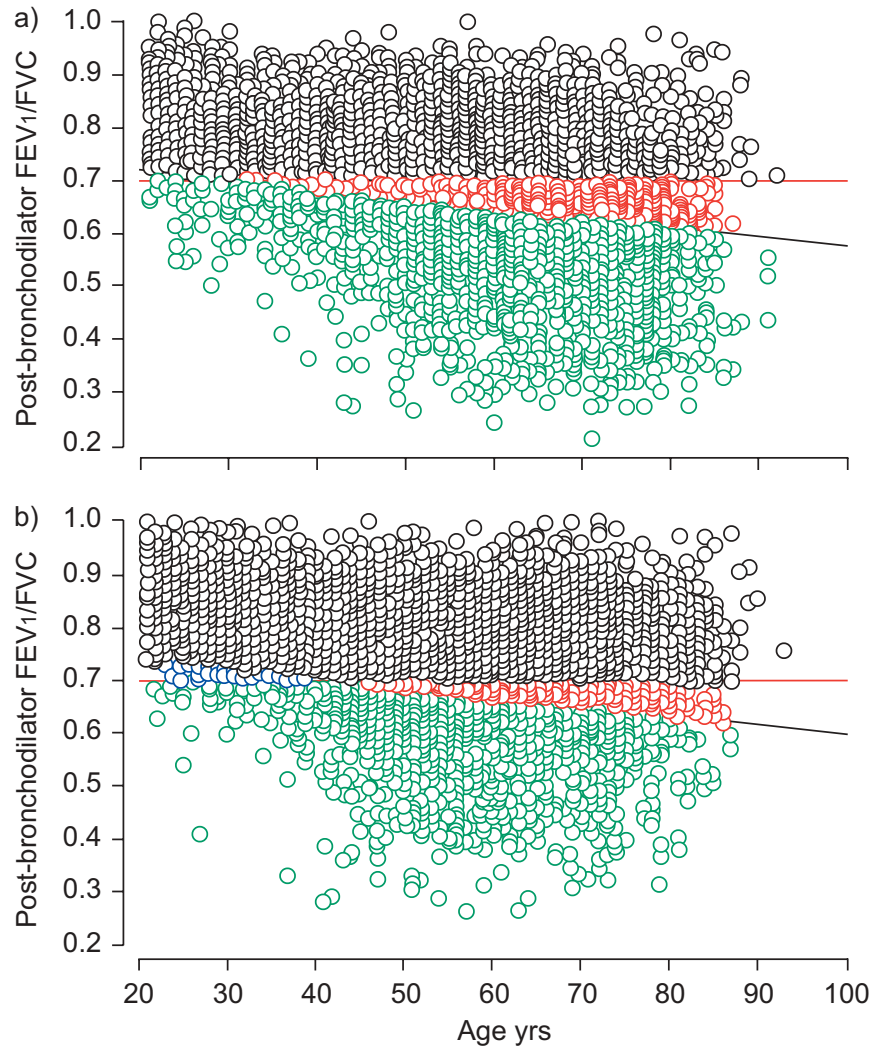

FIGURE 1. Association between forced expiratory volume in one second (FEV1)/forced vital capacity (FVC) and age in symptomatic: a) males ( $n=6,597)$ and $b)$ females $(n=7,459)$. The horizontal red line indicates the fixed $0.70 \mathrm{FEV} 1 / F C$ cut-off point that is currently recommended by all major clinical chronic obstructive pulmonary disease guidelines $[1,5,6,8]$; the black diagonal line indicates the lower limit of normal for healthy nonsmoking males and females, respectively. Green circles: true positive (unique subjects considered to have airflow obstruction according to both definitions); black circles: true negative; red circles: false positive (subjects in whom discordant conclusions regarding the presence of airflow obstruction are drawn); blue circles: false negative.

calculated for the fixed FEV1/FVC definition, considering the LLN definition the gold standard for assessment of airflow obstruction [4]. For these calculations, all subjects with obstruction according to a particular definition (regardless of the severity of obstruction, i.e. mild or moderate-to-very severe obstruction) were combined. The aforementioned diagnostic test characteristics (sensitivity, etc.) were also calculated for the use of pre-bronchodilator spirometry for the demonstration of airflow obstruction compared with the gold standard, i.e. postbronchodilator spirometry.

\section{RESULTS}

\section{Study population}

Spirometric results were available in the primary care laboratory database for 14,056 subjects aged $\geqslant 21$ yrs who had been referred for lung function testing by their GP. Table 1 shows the demographic and lung function characteristics of the males and females in the present study population. At $54.2 \pm 15.2 \mathrm{yrs}$, the males' mean \pm SD age was higher than that 
of the females $(51.9 \pm 15.1 \mathrm{yrs})$. Of all of the subjects, $69.1 \%$ were current or ex-smokers. The post-bronchodilator FEV1/ FVC was $0.73 \pm 0.13$ in males and $0.78 \pm 0.11$ in females.

The subgroup of subjects aged $\geqslant 50$ yrs with a smoking history consisted of $3,473(57.7 \%)$ males and 2,543 females, with a mean \pm SD age of $63.4 \pm 8.8$ yrs (table 1 ). Of these, 1,308 males and 1,195 females (41.6\% of subgroup) were current smokers. The post-bronchodilator FEV1/FVC was $0.68 \pm 0.13$ in the males and $0.73 \pm 0.12$ in the females. Compared with the females in the subgroup, post-bronchodilator FEV1 was lower in males $(72.4 \pm 19.6$ versus $75.7 \pm 19.5 \%$ pred $)$.

\section{Distribution of post-bronchodilator airflow obstruction}

Figure 1 shows the relationship between the FEV1/FVC ratio and age in males and females in the study sample. Both graphs clearly show that the discrepancy between the two definitions of airflow obstruction increases with the age of the subjects. The graphs also show that, particularly in females aged $<40$ yrs, use of the fixed FEV1/FVC ratio cut-off point leads
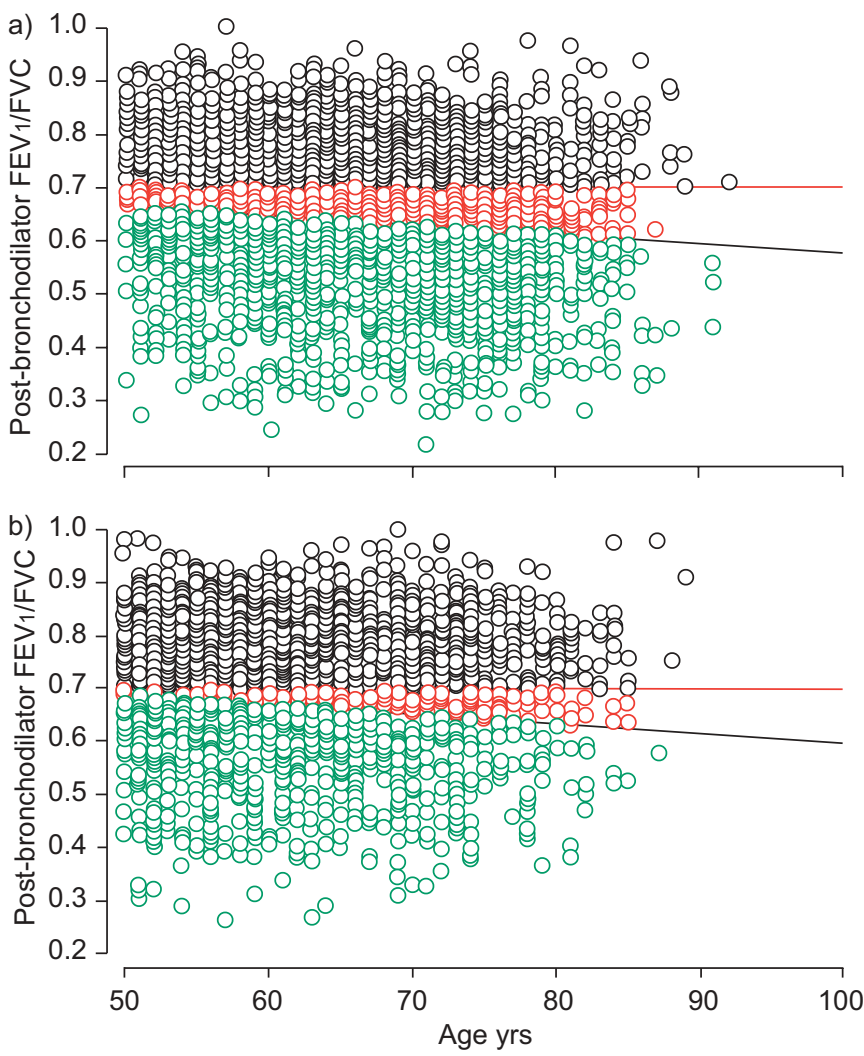

FIGURE 2. Association between forced expiratory volume in one second (FEV1)/forced vital capacity (FVC) and age in symptomatic current and ex-smokers aged $\geqslant 50$ yrs referred for spirometric testing by their general practitioner: a) males $(n=3,473)$; and $b)$ females $(n=2,543)$. The horizontal red line indicates the fixed $0.70 \mathrm{FEV}_{1} / \mathrm{FVC}$ cut-off point that is currently recommended by all major clinical chronic obstructive pulmonary disease guidelines $[1,5,6,8]$; the black diagonal line indicates the lower limit of normal for healthy nonsmoking males and females, respectively. Green circles: true positive (unique subjects considered to have airflow obstruction according to both definitions); black circles: true negative; red circles: false positive (subjects in whom discordant conclusions regarding the presence of airflow obstruction are drawn). to a small number of subjects being unjustly considered to have no airflow obstruction, whereas, according to their sexand age-specific LLN, they do show obstruction. For the subgroup of current or ex-smokers aged $\geqslant 50$ yrs, no such cases were observed (fig. 2).

\section{Agreement between definitions of post-bronchodilator airflow obstruction}

Table 2 shows the concordance and discordance between the fixed FEV1/FVC cut-off point and LLN cut-off point definitions of airflow obstruction. For all male and female study subjects combined, the sensitivity of the fixed cut-off point relative to the LLN cut-off point definition was 97.9\% (95\% CI 97.7-98.1\%), with a specificity 91.2\% (95\% CI 90.7-91.7\%), positive predictive value of $72.0 \%$ (95\% CI $71.3-72.7 \%)$ and negative predictive value of $99.5 \%$ (95\% CI 99.4-99.6\%).

The agreement between the two definitions for the subgroup of current and ex-smokers aged $\geqslant 50$ yrs is shown in table 3 . In this subgroup, the sensitivity of the fixed FEV1/FVC cut-off point relative to the LLN cut-off point definition was $100 \%$, the specificity $82.0 \%(95 \%$ CI $81.0-83.0 \%)$, the positive predictive value $69.2 \%$ (95\% CI $68.0-70.4 \%$ ) and the negative predictive value $100 \%$.

Figure 3 shows the true positive, false positive, true negative and false negative rates of the fixed cut-off point definition in relation to age for the whole study sample. Starting from subjects aged 30 yrs, there was a steady increase in the rate of false positive diagnoses of airflow obstruction. For subjects in the 31-40-yr age stratum, the proportion of false positive diagnoses based on the fixed cut-off point definition was $8.9 \%$ (95\% CI 7.7-10.1\%) of all positive diagnoses. For the other age strata, the proportions of false positive diagnoses using the fixed cut-off point definition were $15.5 \%$ (95\% CI $14.2-16.8 \%$ ) for those aged $41-50 \mathrm{yrs}, 23.9 \%$ (95\% CI 22.4-25.4\%) for those aged $51-60$ yrs, $33.2 \%$ (95\% CI $31.0-35.4 \%$ ) for those aged $61-$ $70 \mathrm{yrs}, 38.7 \%$ (95\% CI 35.7-41.7\%) for those aged 71-80 yrs and $42.7 \%$ (95\% CI $37.3-48.1 \%)$ for those aged $\geqslant 81$ yrs $(\mathrm{p}<0.001$ in Chi-squared test).

Figure 4 shows the prevalence of post-bronchodilator airflow obstruction by diagnostic definition and age group for the total study population.

\section{Airflow obstruction with pre-bronchodilator versus post- bronchodilator spirometry}

Table 4 shows the concordance and disconcordance between pre- and post-bronchodilator rates of airflow obstruction for the fixed cut-off point definition (i.e. FEV1/FVC of $<0.70$ versus $\mathrm{FEV} 1 / \mathrm{FVC}$ of $\geqslant 0.70$ ). For the total study population, the sensitivity of an observed pre-bronchodilator airflow obstruction was $94.5 \%$ (95\% CI 94.1-94.9\%), with a specificity of $89.0 \%$ (95\% CI $88.5-89.5 \%)$, positive predictive value of $74.7 \%$ (95\% CI 74.0-75.4) and negative predictive value of $97.9 \%$ (95\% CI 97.7-98.1\%). In the subgroup of current and exsmokers aged $\geqslant 50 \mathrm{yrs}$, the corresponding figures were $94.6 \%$ (95\% CI 94.0-95.2\%), 87.4\% (95\% CI 86.6-88.2\%), 84.2\% (95\% CI $83.3-85.1 \%$ ) and $95.8 \%$ (95\% CI 95.3-96.3\%), respectively (data not shown). 
TABLE 2 Comparison of definitions by level of obstruction ${ }^{\#}$

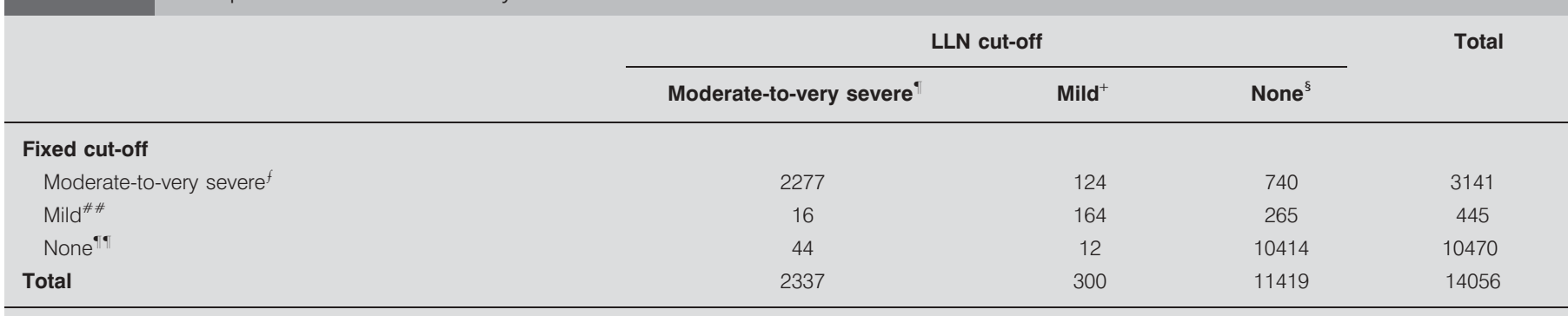

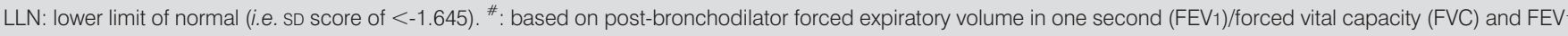

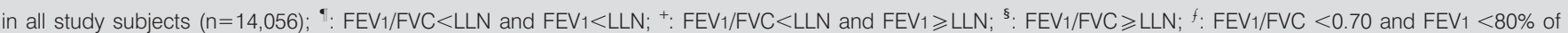
predicted value; ${ }^{\# \#}$ : FEV1/FVC $<0.70$ and FEV $1 \geqslant 80 \%$ pred; $"{ }^{\prime}$ : FEV $1 / F V C \geqslant 0.70$.

TABLE 3 Comparison of definitions by level of obstruction* in the older current and ex-smoker subgroup"

\begin{tabular}{|c|c|c|c|c|}
\hline & \multicolumn{3}{|c|}{ LLN cut-off } & Tota \\
\hline Moderate-to-very severe ${ }^{\# \#}$ & 1552 & 100 & 571 & 2223 \\
\hline Mild & 0 & 78 & 199 & 227 \\
\hline None $^{++}$ & 0 & 0 & 3516 & 3516 \\
\hline
\end{tabular}

LLN: lower limit of normal (i.e. SD score of $<-1.645)$. *: based on post-bronchodilator forced expiratory volume in one second (FEV1)/forced vital capacity (FVC) and FEV 1

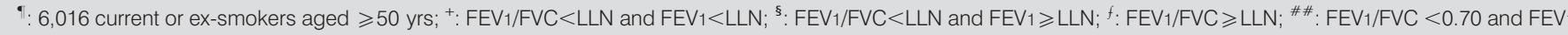
$<80 \%$ of predicted value; ${ }^{\top}$ : FEV1/FVC $<0.70$ and $\mathrm{FEV}_{1} \geqslant 80 \%$ pred; ${ }^{++}$: FEV $1 / \mathrm{FVC} \geqslant 0.70$

\section{DISCUSSION}

In the present study, diagnostic outcomes were compared when two recommended but different definitions of airflow obstruction based on FEV1/FVC were applied in a large

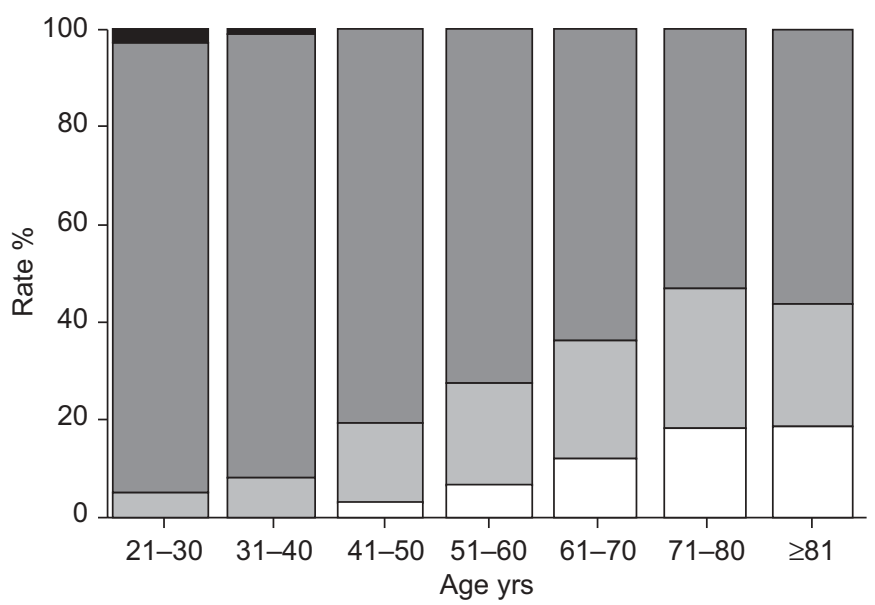

FIGURE 3. Concordant and discordant classification of airflow obstruction in 14,056 adult males and females referred for spirometric testing by their general practitioner when comparing the 0.70 fixed forced expiratory volume in one second/ forced vital capacity ratio cut-off point definition with the sex-and age-specific lower limit of normal cut-off point as the gold standard definition. $\square$ : false positive; $\mathbb{1}$ : true positive; $\mathbf{n}$ : true negative; $\mathbf{\square}$ : false negative. population of subjects without a prior diagnosis of chronic respiratory disease referred for diagnostic spirometry by their GP. The present findings show that the older such subjects are, the more pronounced the discrepancy between the widely recommended 0.70 fixed FEV1/FVC cut-off point and a sexand age-specific LLN cut-off point for this ratio becomes. Although the negative predictive value of the fixed ratio definition was very high $(99.4 \%$ for the whole sample and $100 \%$ for the subgroup of older current and ex-smokers with a high prior probability of COPD), the positive predictive value of the fixed ratio was insufficient $(72.0 \%$ overall and $69.2 \%$ in the aforementioned subgroup). Since spirometry is used as a diagnostic test for the verification of obstruction (rather than its exclusion), these predictive values are insufficient. When using the fixed FEV1/FVC cut-off point definition in middle-aged and elderly current or ex-smokers, at least a quarter of all subjects with airflow obstruction should be considered false positives when sex and age are taken into account. This clearly has implications for the GP's diagnostic interpretation in individuals who present with respiratory symptoms, and, consequently, may have an undesirable impact upon those who are incorrectly confronted with a positive diagnosis of COPD and are treated as such. Conversely, it is important to realise that, in daily practice, there will always be the risk of false positive and false negative results, especially in the borderline area between normal and abnormal function. Careful follow-up of patients and confirmation of the initial result can largely overcome this. 


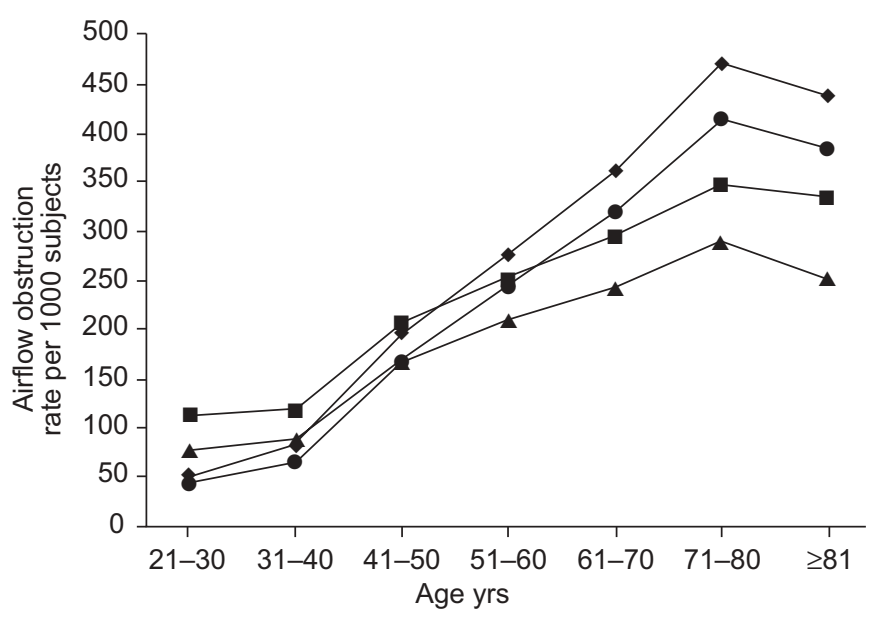

FIGURE 4. Prevalence of post-bronchodilator airflow obstruction in the total study population $(n=14,056)$, by age group and diagnostic definition. $\bullet$ : fixed forced expiratory volume in one second (FEV1)/forced vital capacity (FVC) cut-off of $<0.70$; $:$ FEV1/FVC of $<0.70$ plus FEV1 $\leqslant 50 \%$ pred (Global Initiative for Chronic Obstructive Lung Disease stages II-IV); $\mathbf{\square}$ : FEV1/FVC $<88 \%$ of predicted value in males and $<89 \%$ pred in females; $\boldsymbol{\Delta}$ : lower limit of normal of FEV $1 / F V C$ cut-off.

Use of pre-bronchodilator instead of post-bronchodilator spirometry to demonstrate airflow obstruction in the present study population resulted in an acceptable outcome with regard to sensitivity and negative predicted value, but also in a less favourable outcome with regard to specificity and, especially, positive predictive value; the rate of false positive interpretations of obstruction when using the fixed $0.70 \mathrm{FEV} 1 /$ FVC cut-off point was $25.3 \%$ in the present total study population of symptomatic subjects, and $15.8 \%$ in the subgroup of symptomatic current or ex-smokers aged $\geqslant 50$ yrs. Similar rates of overestimation of the prevalence of airflow obstruction have previously been reported in general population studies [23, 24].

\section{Comparison with existing literature}

The main origin of the choice of the arbitrary 0.70 fixed FEV1/ FVC cut-off point is probably the publication of the first Global Initiative for Chronic Obstructive Lung Disease (GOLD) workshop report in 2001 [7]. Ever since its publication, the GOLD

\begin{tabular}{|c|c|c|c|}
\hline \multirow[t]{3}{*}{ TABLE 4} & \multicolumn{3}{|c|}{$\begin{array}{l}\text { Concordance and disconcordance of rates of } \\
\text { pre- and post-bronchodilator airflow obstruction } \\
\text { in all study subjects }{ }^{\#}\end{array}$} \\
\hline & \multicolumn{2}{|c|}{ Post-bronchodilator FEV $1 / F V C$} & \multirow[t]{2}{*}{ Total } \\
\hline & Obstruction & No obstruction ${ }^{+}$ & \\
\hline \multicolumn{4}{|c|}{ Pre-bronchodilator FEV $1 / F V C$} \\
\hline Obstruction & 3390 & 1149 & 4539 \\
\hline No obstruction & 196 & 9321 & 9517 \\
\hline Total & 3586 & 10470 & 14056 \\
\hline
\end{tabular}

Data are presented as $\mathrm{n}$. FEV1: forced expiratory volume in one second; FVC: forced vital capacity. ${ }^{*}: \mathrm{n}=14,056 ;{ }^{\bullet}:$ FEV $1 / F V C$ of $<0.70 ;{ }^{+}:$FEV $1 / F V C$ of $\geqslant 0.70$. guideline has served as the point of departure for many other COPD guidelines around the world, including the National Institute for Health and Clinical Excellence guideline [1]. However, the initial 2001 GOLD workshop report had already stated that the proposed classification system for airflow obstruction was a "pragmatic approach aimed at practical implementation and should only be regarded as an educational tool" [7]. In the latest update of the GOLD guideline (2006), the authors emphasise that the recommended fixed FEV1/FVC cutoff point (as well as the percentage predicted FEV1 cut-off points for COPD severity staging) is recommended for the sake of simplicity, and that the use of the fixed 0.70 value may result in overdiagnosis of COPD in the elderly. In the present authors' view, there is now sufficient scientific evidence from a number of different population studies [13-18] showing that undifferentiated use of the fixed 0.70 cut-off point for the FEV1/FVC is afflicted with an age bias that may lead to an unacceptably high proportion of middle-aged and elderly subjects being unjustly diagnosed with airflow obstruction. The present real-life data from subjects referred by their GP with a directed indication for a diagnostic spirometric test confirm this presumption. Although it is obvious that the fixed FEV1/FVC ratio cut-off point definition is a very convenient way of defining airflow obstruction, the resultant mismatch between the simplicity and the unfavourable rate of false positive results for the main diagnostic criterion for COPD should definitely give rise to reconsideration of this approach [25].

It was recently reported that subjects classified as normal when applying the LLN definition but as obstructive when applying the fixed ratio are more likely to die and show a higher risk of COPD related hospitalisation during follow-up [26]. Although this is an interesting observation, the study distracts from the real debate, since demonstration of airflow obstruction in the work-up involved in diagnosing chronic respiratory conditions is quite a different thing from using lung function measurements for the prediction of mortality or hospital admission [27]. Other conditions that influence respiratory function (e.g. heart failure) are likely to be responsible for the increased risk of mortality and hospitalisation in such patients. COPD patients with mild obstruction according to the fixed FEV1/ FVC definition show significant physiological limitation as regards exercise capacity [28], which raises the possibility that even mild abnormality in lung function may be important in some circumstances. This should be all the more reason to make sure that sex and, particularly, age are taken into account when defining (mild) airflow obstruction.

\section{Strengths and limitations}

To the best of the present authors' knowledge, the present study is the first to analyse post-bronchodilator spirometric results obtained in a primary care population with a wide age range. The GPs considered a spirometric test indicated as a part of their diagnostic work-up in individuals who presented with symptoms that may point to a chronic respiratory condition. In contrast with the population screening studies that have recently been reported [15-18], the subjects in the present study population had a higher prior probability of underlying chronic respiratory illness and truly reflect the group of people in which spirometry is applied in primary care practice. One limitation of the present study was that it was not 
possible to check the quality of the spirometric test according to current standards [29]. Conversely, poor-quality spirometric tests are often interpreted nonetheless, and poor test performance will affect the outcome of both definitions of airflow obstruction equally. A final limitation was that follow-up data were not yet available for the present study subjects; only time can tell whether or not the subjects will exhibit the progressive lung function decline that is typical of COPD.

One aspect that should be borne in mind when reconsidering the choice of a more rational definition of airflow obstruction is that physicians and nurses may lack sufficient biostatistical knowledge to fathom approaches based on reference population distributions [30]. Conversely, there are examples of using LLN approaches in medical practice, for instance when expressing the results of bone mineral density measurements for osteoporosis [31] and assessing thinness or overweight in children and adolescents [32, 33]. Contemporary electronic spirometers and spirometric software should be able to support its interpretation if a more sophisticated definition of airflow obstruction were to be used in clinical practice. Several spirometers that calculate, show and print LLN and/or SD scores are commercially available.

It is important to realise that the choice of definition of airflow obstruction also has a substantial impact on prevalence rates of obstructive lung disease. Depending upon the definition used, population prevalence rates for COPD may double, or even triple, as a consequence of the age bias in the fixed ratio definition of airflow obstruction [34-36]. The present findings, as depicted in figure 4, suggest a similar increase in positive diagnosis of airflow obstruction in subjects who seek medical care because of respiratory symptoms.

\section{Conclusion}

In conclusion, the previously reported sex and age dependency of the forced expiratory volume in one second/forced vital capacity ratio, the main criterion for demonstrating airflow obstruction when diagnosing chronic obstructive pulmonary disease, leads to substantial overdiagnosis of obstruction in the middle aged and elderly. In both males and females, the rate of false positive diagnoses increases with age when the widely recommended fixed 0.70 forced expiratory volume in one second/forced vital capacity cut-off point is used. As in previously reported population studies, the use of pre- instead of post-bronchodilator spirometry leads to overestimation of the prevalence of airflow obstruction in subjects who present to their general practitioner with respiratory symptoms. Although diagnosis of chronic obstructive pulmonary disease obviously requires more than a spirometric test (i.e. symptoms, smoking history and additional diagnostic tests), a definition of airflow obstruction that is based on lower limits of normal from an appropriate reference population would diminish the rate of false positive interpretations. The individual, as well as the societal, burden of chronic obstructive pulmonary disease is sufficiently large to warrant critical appraisal of the main criterion on which the diagnosis of this disease is based.

\section{ACKNOWLEDGEMENTS}

The authors wish to express their thanks to the lung function technicians of the General Practice Laboratory Foundation Etten-Leur/Breda (Etten-Leur, the Netherlands; SHL) who performed the spirometric tests, and to $H$. van Meelis (Radboud University Nijmegen Medical Centre, Nijmegen, the Netherlands) and M. Louisa and A. de Been (SHL) for extracting the spirometric and medical history data from the SHL databases. The authors also appreciate the statistical advice of R. Akkermans (Dept of General Practice, Radboud University Nijmegen Medical Centre).

\section{REFERENCES}

1 National Institute for Clinical Excellence. Chronic obstructive pulmonary disease: national clinical guideline for management of chronic obstructive pulmonary disease in adults in primary and secondary care. Thorax 2004; 59: Suppl. I, i1-i232.

2 Buist AS, McBurnie MA, Vollmer WM, et al. International variation in the prevalence of COPD (the BOLD study): a population-based prevalence study. Lancet 2007; 370: 741-750.

3 Poels PJ, Schermer TR, van Weel C, Calverley PM. Spirometry in chronic obstructive pulmonary disease. BMJ 2006; 333: 870-871.

4 Pellegrino R, Viegi G, Brusasco V, et al. Interpretative strategies for lung function tests. Eur Respir J 2005; 26 948-968.

5 Bellamy D, Bouchard J, Henrichsen S, et al. International Primary Care Respiratory Group (IPCRG) guidelines: management of chronic obstructive pulmonary disease (COPD). Prim Care Respir J 2006; 15: 48-57.

6 Smeele IJM, van Weel C, van Schayck CP, et al. NHG standaard COPD. Tweede herziening. [NHG standard on COPD. Second revision.]. Huisarts Wet 2007; 50: 362-379.

7 Global Initiative for Chronic Obstructive Lung Disease. Global Strategy for the Diagnosis, Management and Prevention of Chronic Obstructive Pulmonary Disease. Executive Summary. www.goldcopd.com/Guidelineitem.asp?11= 2\&12=1\&intId=996 Date last updated: January 2008. Date last accessed: January 7, 2008.

8 Celli BR, MacNee W. Standards for the diagnosis and treatment of patients with COPD: a summary of the ATS/ ERS position paper. Eur Respir J 2004; 23: 932-946.

9 Janssens JP, Pache JC, Nicod LP. Physiological changes in respiratory function associated with ageing. Eur Respir J 1999; 13: 197-205.

10 Enright PL, Kronmal RA, Higgins M, Schenker M, Haponik EF. Spirometry reference values for women and men 65 to 85 years of age. Cardiovascular health study. Am Rev Respir Dis 1993; 147: 125-133.

11 Hankinson JL, Odencrantz JR, Fedan KB. Spirometric reference values from a sample of the general U.S. population. Am J Respir Crit Care Med 1999; 159: 179-187.

12 Quanjer PH, Tammeling GJ, Cotes JE, Pedersen OF, Peslin R, Yernault JC. Lung volumes and forced ventilatory flows. Report Working Party Standardization of Lung Function Tests European Community for Steel and Coal. Eur Respir J 1993; 6: Suppl. 16, 5-40.

13 Schmidt CD, Dickman ML, Gardner RM, Brough FK Spirometric standards for healthy elderly men and women. Am Rev Respir Dis 1973; 108: 933-939.

14 Milne JS, Williamson J. Respiratory function tests in older people. Clin Sci 1972; 42: 371-381. 
15 Roberts SD, Farber MO, Knox KS, et al. FEV1/FVC ratio of $70 \%$ misclassifies patients with obstruction at the extremes of age. Chest 2006; 130: 200-206.

16 Hardie JA, Buist AS, Vollmer WM, Ellingsen I, Bakke PS, Morkve O. Risk of over-diagnosis of COPD in asymptomatic elderly never-smokers. Eur Respir J 2002; 20: 1117-1122.

17 Shirtcliffe P, Weatherall M, Marsh S, et al. COPD prevalence in a random population survey: a matter of definition. Eur Respir J 2007; 30: 232-239.

18 Hnizdo E, Glindmeyer HW, Petsonk EL, Enright P, Buist AS. Case definitions for chronic obstructive pulmonary disease. COPD 2006; 3: 95-100.

19 Rutten FH, Cramer MJ, Grobbee DE, et al. Unrecognized heart failure in elderly patients with stable chronic obstructive pulmonary disease. Eur Heart J 2005; 26: 1887-1894.

20 American Thoracic Society. Standardization of Spirometry, 1994 Update. Am J Respir Crit Care Med 1995; 152: 1107-1136.

21 Quanjer PH. SpirXpert. Reference values for adults. http://www.spirxpert.com/epidemiol7.htm Date last accessed: October 1, 2007.

22 Knottnerus JA, van Weel C, Muris JW. Evidence base of clinical diagnosis: evaluation of diagnostic procedures. BMJ 2002; 324: 477-480.

23 Johannessen A, Omenaas ER, Bakke PS, Gulsvik A. Implications of reversibility testing on prevalence and risk factors for chronic obstructive pulmonary disease: a community study. Thorax 2005; 60: 842-847.

24 Perez-Padilla R, Hallal PC, Vazquez-Garcia JC, et al. Impact of bronchodilator use on the prevalence of COPD in population-based samples. COPD 2007; 4: 113-120.

25 Enright P, Quanjer P. Spirometry for COPD is both underutilized and overutilized. Chest 2007; 132: 368-370.
26 Mannino DM, Buist AS, Vollmer WM. Chronic obstructive pulmonary disease in the older adult: what defines abnormal lung function? Thorax 2006; 62: 237-241.

27 Pellegrino R, Brusasco V, Viegi G, et al. Definition of COPD: based on evidence or opinion? Eur Respir J 2008; 31: 681-682.

28 Ofir D, Laveneziana P, Webb KA, Lam YM, O'Donnell DE. Mechanisms of dyspnoea during cycle exercise in symptomatic patients with GOLD stage I chronic obstructive pulmonary disease. Am J Respir Crit Care Med 2008; 177: 622-629.

29 Miller MR, Hankinson J, Brusasco V, et al. Standardisation of spirometry. Eur Respir J 2005; 26: 319-338.

30 Windish DM, Huot SJ, Green ML. Medicine residents' understanding of the biostatistics and results in the medical literature. JAMA 2007; 298: 1010-1022.

31 Elders PJM, Leusink GL, Graafmans WC, et al. NHG standaard osteoporose. [NHG standard on osteoporosis.]. Huisarts Wet 2005; 48: 559-570.

32 Cole TJ, Flegal KM, Nicholls D, Jackson AA. Body mass index cut offs to define thinness in children and adolescents: international survey. BMJ 2007; 335: 194.

33 Cole TJ, Bellizzi MC, Flegal KM, Dietz WH. Establishing a standard definition for child overweight and obesity worldwide: international survey. BMJ 2000; 320: 1240-1243.

34 Lundback B, Lindberg A, Lindstrom M, et al. Not 15 but $50 \%$ of smokers develop COPD? - Report from the Obstructive Lung Disease in Northern Sweden studies. Respir Med 2003; 97: 115-122.

35 Schermer TR, Quanjer PH. COPD screening in primary care: who is sick? Prim Care Respir J 2007; 16: 49-53.

36 Celli BR, Halbert RJ, Isonaka S, Schau B. Population impact of different definitions of airway obstruction. Eur Respir J 2003; 22: 268-273. 